\title{
Neonatal hematological parameters and the risk of moderate-severe bronchopulmonary dysplasia in extremely premature infants
}

\author{
Xueyu Chen ${ }^{1}$, Huitao Li ${ }^{1}$, Xiaomei Qiu', Chuanzhong Yang ${ }^{1 *}$ and Frans J. Walther ${ }^{2,3^{*}}$
}

\begin{abstract}
Objective: To evaluate the association between hematological parameters at birth and the risk of moderate-severe bronchopulmonary dysplasia (BPD) in a cohort of extremely preterm infants.

Methods: This is a retrospective study of all extremely premature infants admitted to the neonatal intensive care unit, Shenzhen Maternity and Child Healthcare Hospital from January 2016 to May 2018. Extremely prematurity was defined as a delivery at a gestational age $\leq 28$ weeks or a birth weight $\leq 1000 \mathrm{~g}$. BPD was diagnosed if oxygen exposure exceeded 28 days and the severity was decided at 36 weeks PMA or discharge. Multivariable analysis was performed to assess the independence of the association between hematological parameters at birth and risk of moderate or severe BPD.

Results: A total of 115 extremely premature infants were analyzed in this study. The median platelet count, neutrophil and monocyte count at birth were significantly higher in infants with moderate-severe BPD compared to infants without BPD (228 vs $194^{*} 10^{9} / \mathrm{I}, P=0.004 ; 5.0$ vs $2.95^{*} 10^{9} / \mathrm{I}, P=0.023 ; 0.88$ vs $0.63^{*} 10^{9} /, P=0.026$, respectively) whereas the mean platelet volume was significantly lower in infants with moderate-severe BPD than those without BPD ( 9.1 vs $9.4 \mathrm{fl}$, $P=0.002$ ). After adjusting for covariates, the risk of moderate-severe BPD was independently associated with platelet count $\geq 207^{*} 10^{9} /$ (odds ratio $3.794,95 \%$ confidence interval: $1.742-8.266, P=0.001$ ).

Conclusion: Our findings suggest that hematologic parameters at birth are different in extremely preterm infants who will develop moderate-severe BPD. A higher platelet count at birth may increase the risk of moderate-severe BPD after extremely premature birth.
\end{abstract}

Keywords: Extremely prematurity, Bronchopulmonary dysplasia, Hematology, Platelets

\section{Introduction}

Bronchopulmonary dysplasia (BPD) affects around 50\% of extremely preterm infants $[1,2]$. Over the past decades, the survival rate of extremely preterm infants has remarkably increased due to the improvement in perinatal care, such as surfactant therapy and ventilation strategies [3]. Concomitantly, the number of new BPD cases is steadily increasing [4].

\footnotetext{
* Correspondence: yangczgd@163.com; fjwalther@ucla.edu

1 Department of Neonatology, Affiliated Shenzhen Maternity \& Child Healthcare Hospital, Southern Medical University, Shenzhen, China

${ }^{2}$ Department of Pediatrics, David Geffen School of Medicine, University of

California Los Angeles, Los Angeles, CA, USA

Full list of author information is available at the end of the article
}

The pathogenesis of BPD is largely attributed to the arrested lung development in these extreme preemies [5]. Gestational age at birth is thus of paramount important for the risk of BPD provided that preterm birth interrupts the programmed pulmonary development during intrauterine life [6]. BPD is nearly-always present in survivals from gestations less than 23 weeks (saccular stage of lung development) [7], whereas the risk of BPD in infants born after 30 weeks of gestation steeply declines to $1 \%[8]$.

Currently, BPD is thought to begin during the first days of life $[9,10]$. The identification of high risk infants therefore facilitates timely intervention to reduce the

(c) The Author(s). 2019 Open Access This article is distributed under the terms of the Creative Commons Attribution 4.0 International License (http://creativecommons.org/licenses/by/4.0/), which permits unrestricted use, distribution, and 
occurrence of BPD. In preterm infants, hematologic testing is routinely performed at birth to evaluate the neonatal condition. Different types of blood cells play an important role in pulmonary inflammation and associated lung injury in preterm infants [11]. Carlo Dani et. al and F. Cekmez et. al both reported a high level of mean platelet volume (MPV) in the first days of life is associated with increased risk of BPD in preterm infants $[9,12]$. However, the association between hematologic parameters at birth and the risk of BPD in extremely premature infants remains elusive. Therefore, the purpose of this study was to investigate clinical hematologic parameters at birth and their association with moderate and severe BPD in a cohort of extremely preterm infants.

\section{Methods and materials}

\section{Study design and population}

This is a retrospective study performed at the Neonatal Intensive Care Unit (NICU), Shenzhen Maternity and Child Healthcare Hospital from January 2016 to May 2018. This study was approved by the institutional ethic committee. All extremely preterm infants cared for in our center were included in the present study. We excluded neonates due to major congenital anomalies and death prior to the diagnosis of BPD.

\section{Definition of clinical variables}

Extreme prematurity was defined as a delivery at a gestational age $\leq 28$ weeks or a birth weight $\leq 1000 \mathrm{~g}$. The diagnosis and severity of BPD in preterm birth was assessed using the consensus definition of National Institute of Child Health and Human Development (NICHD).
Briefly, BPD was diagnosed when supplemental oxygen was needed for more than 28 days and the severity was assessed according to the oxygen concentration required at 36 weeks PMA or discharge [13, 14]. (Suspected) Early-onset neonatal sepsis occurring within the first $72 \mathrm{~h}$ of life was defined as the following criteria: a positive culture of blood and/or the presence of clinical signs of infection with abnormal chest radiograph profiles, hematological features and maternal risk factors [15].

\section{Data collection}

The following data were retrieved from the electronic medical record, including maternal age, mode of conception, maternal complications such as gestational hypertension and gestational diabetes mellitus (GDM), premature prelabor rupture of membranes (PPROM), chorioamnionitis, small for gestational age (SGA), antenatal steroid, delivery methods, need for resuscitation, gestational age (GA), birth weight (BW), Apgar score, sex, whole blood test at birth, neonatal respiratory distress syndrome (NRDS), surfactant treatment, ventilation mode, patent ductus arteriosus (PDA) and (suspected) early onset neonatal sepsis, intraventricular hemorrhage (IVH), necrotizing enterocolitis (NEC) and pulmonary hemorrhage. Antenatal steroid treatment was considered if at least one dose of dexamethasone was administrated $12 \mathrm{~h}$ prior to delivery. Surfactant treatment was recorded if at least one course of surfactant was administrated. Blood testing was performed on Mindray 5390 (Shenzhen, China) using the samples collected within $3 \mathrm{~h}$ after birth from the umbilical venous or umbilical artery catheter of the infants.

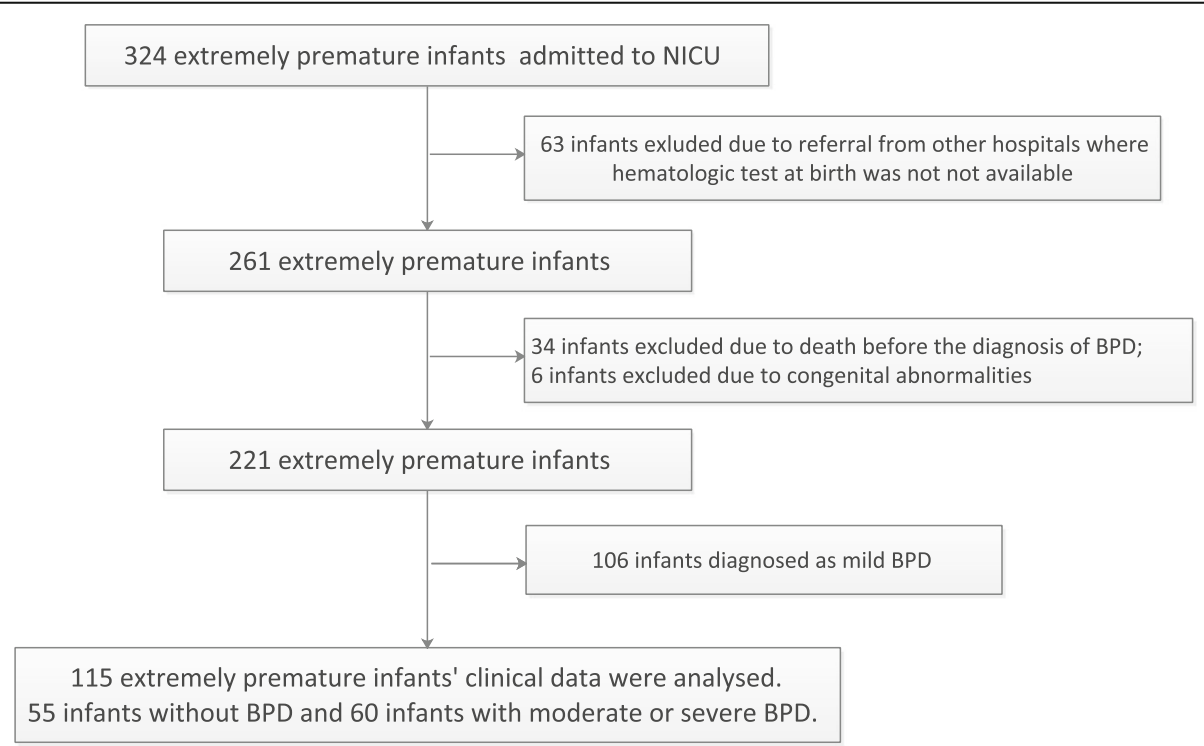

Fig. 1 Flowchart of cases selection and analysis. 115 extremely premature infants were enrolled in this study. BPD, bronchopulmonary dysplasia. NICU, neonatal intensive care unit 


\section{Statistics}

The sample size calculation was based on the platelet count from our clinical laboratory. At $90 \%$ power and $\alpha=0.05,51$ infants in each group would be sufficient to detect a significant difference. Hematologic parameters were expressed as median [interquartile range (IQR)]. The Shapiro-Wilk test was used to evaluate the normality of continuous variables. Unpaired $t$ test or Mann-Whitney $U$ test was adopted to analyze continuous variables, as appropriate. Chi-square or Fisher's exact test were used to compare categorical data, as appropriate. Multivariate logistic regression was performed to determine the independent risk factors of moderate or severe BPD. The odds ratios (OR) and 95\% confidence interval (CI) were calculated in logistic regression analysis. Afterwards, receiver-operator curve (ROC) was applied to calculate the cut-off values to dichotomize the corresponding continuous variables significantly related to the occurrence of moderate or severe BPD in multivariate logistic regression analysis. Finally, univariable logistic regression model was built to find the independent risk factors for the occurrence of moderate or severe BPD and its related morbidities.

\section{Ethical statement}

The Shenzhen Maternity and Child Healthcare Hospital Institutional Ethical Committee (IEC) approved the collection and usage of the clinical information for research purposes and waived the requirement for informed consent (IEC No. [2018]-082).

\section{Results}

A total of 318 extremely premature infants were admitted to our NICU during the study period. Diagnosis of BPD was made in 166 (75\%) infants in which 106 (48\%) infants were categorized as mild BPD and $60(27 \%)$ as moderate-severe BPD (Fig. 1). After applying exclusion criteria, 115 extremely premature infants were included in this study, in which 97 (84\%) were born before 28 weeks and $18(16 \%)$ born after 28 weeks with birthweight lower than $1000 \mathrm{~g}$. The median of GA at birth was 26.4 (IQR: 25.1-27.6) weeks. The clinical characteristics are summarized in Table 1.

Univariable analysis showed that the moderate-severe BPD group had higher rate of conception by ART (27\% vs $7 \%$ ), intubation at resuscitation ( $88 \%$ vs $45 \%)$, mechanical ventilation ( $85 \%$ vs $40 \%$ ), (suspected) early onset neonatal sepsis ( $43 \%$ vs $16 \%$ ), PDA ( $58 \%$ vs $18 \%$ ) and surfactant treatment ( $88 \%$ vs $59 \%$, Table 1$)$. In addition, infants with moderate-severe BPD had lower gestational age ( 25.8 vs 27.3 weeks), birth weight (770 vs $890 \mathrm{~g}$ ) and 1-min Apgar score (5 vs 7), as well as lower rate of gestational hypertension ( $5 \%$ vs $16 \%$ ), chorioamnionitis ( $3 \%$
Table 1 Clinical characteristics by bronchopulmonary dysplasia status

\begin{tabular}{|c|c|c|c|}
\hline Variable & $\begin{array}{l}\text { Infants without } \\
\text { BPD }(n=55)\end{array}$ & $\begin{array}{l}\text { Infants with } \\
\text { moderate or } \\
\text { severe BPD } \\
(n=60)\end{array}$ & $P$ value \\
\hline maternal age, yr & $32(29-36)$ & $32(29-34)$ & 0.406 \\
\hline conception by ART & $4(7 \%)$ & $16(27 \%)$ & 0.006 \\
\hline GDM & $3(6 \%)$ & $4(7 \%)$ & 0.786 \\
\hline gestational hypertension & $9(16 \%)$ & $3(5 \%)$ & 0.046 \\
\hline PPROM & $13(24 \%)$ & $24(40 \%)$ & 0.061 \\
\hline chorioamnionitis & $6(11 \%)$ & $2(3 \%)$ & 0.015 \\
\hline $\begin{array}{l}\text { Intubation at } \\
\text { resuscitation }\end{array}$ & $25(45 \%)$ & $53(88 \%)$ & $<0.001$ \\
\hline $\begin{array}{l}\text { antenatal steroid } \\
\text { treatment }\end{array}$ & $37(67 \%)$ & 49 (82\%) & 0.076 \\
\hline $\begin{array}{l}\text { cesarean section } \\
\text { delivery }\end{array}$ & $25(46 \%)$ & $10(17 \%)$ & 0.001 \\
\hline $\begin{array}{l}\text { gestational age at } \\
\text { birth, wk }\end{array}$ & $27.3(26.1-28.6)$ & $25.8(24.5-26.8)$ & $<0.001$ \\
\hline birth weight, gr & $890(740-980)$ & $770(687-910)$ & 0.039 \\
\hline SGA & $18(33 \%)$ & $5(8 \%)$ & 0.001 \\
\hline male & $26(47 \%)$ & $39(65 \%)$ & 0.055 \\
\hline NRDS & $43(78 \%)$ & $54(90 \%)$ & 0.081 \\
\hline Mechanical ventilation & $22(40 \%)$ & $51(85 \%)$ & $<0.001$ \\
\hline $\begin{array}{l}\text { (Suspected) Early-onset } \\
\text { neonatal sepsis }\end{array}$ & $9(16 \%)$ & $26(43 \%)$ & 0.002 \\
\hline Apgar score at 1 min & $7(5-9)$ & $5(5-8)$ & 0.041 \\
\hline Apgar score at 5 min & $10(9-10)$ & $10(8-10)$ & 0.133 \\
\hline surfactant treatment & $32(59 \%)$ & $53(88 \%)$ & $<0.001$ \\
\hline PDA & $10(18 \%)$ & $35(58 \%)$ & $<0.001$ \\
\hline IVH grade 3 or 4 & $5(9 \%)$ & $9(15 \%)$ & 0.333 \\
\hline NEC & $2(4 \%)$ & $3(5 \%)$ & 0.541 \\
\hline pneumothorax & $1(2 \%)$ & $1(2 \%)$ & 0.950 \\
\hline $\begin{array}{l}\text { pulmonary } \\
\text { hemorrhage }\end{array}$ & $2(4 \%)$ & $4(7 \%)$ & 0.681 \\
\hline
\end{tabular}

Data were displayed as median (interquartile range) or number (percentage). $A R T$ assisted reproductive technology, GDM gestational diabetes mellitus, PPROM preterm premature rupture of the membranes, SGA small for gestational age, NRDS neonatal respiratory distress syndrome, PDA patent ductus arteriosus, IVH intraventricular hemorrhage, NEC necrotizing enterocolitis

vs $11 \%)$, cesarean section delivery (17\% vs $46 \%)$ and SGA ( $8 \%$ vs $33 \%$, Table 1$)$.

The comparison of hematologic parameters at birth between infants without BPD and with moderate or severe BPD was displayed in Table 2. The platelet count, neutrophils count and percentage, monocyte count and percentage were significantly higher in infants with moderate or severe BPD compared with no BPD infants (228 vs $194 * 10^{9} / 1, p=0.004 ; 5.0$ vs $2.95 * 10^{9} / 1, p=0.023$; $49.1 \%$ vs $37.4 \%, p=0.032$; 0.88 vs $0.63{ }^{*} 10^{9} / \mathrm{l}, p=0.026$ and $8.0 \%$ vs $6.8 \%, p=0.04$, respectively). The mean platelet 
Table 2 Hematologic features at birth by bronchopulmonary dysplasia status

\begin{tabular}{|c|c|c|c|}
\hline Variables & Infants without $\mathrm{BPD}(n=55)$ & Infants with moderate or severe BPD $(n=60)$ & $P$ value \\
\hline$\overline{\text { WBC count }, 10^{9} / \mathrm{I}}$ & $9.12(6.28-15.89)$ & $11.2(6.9-20.9)$ & 0.141 \\
\hline RBC count, $10^{12} / \mid$ & $4.22(3.74-4.59)$ & $4.2(3.9-4.5)$ & 0.523 \\
\hline platelet count, $10^{9} / 1$ & $194.00(131.00-245.00)$ & $228(189-259)^{* *}$ & 0.004 \\
\hline Neutrophils count, $10^{9} / /$ & $2.95(1.68-6.46)$ & $5.0(2.4-13.1)^{*}$ & 0.023 \\
\hline lymphocyte count, $10^{9} / /$ & $4.14(3.17-6.94)$ & $4.1(3.0-6.7)$ & 0.675 \\
\hline Eosinophil count, $10^{9} / 1$ & $0.12(0.05-0.18)$ & $0.11(0.06-0.22)$ & 0.492 \\
\hline Basophil count, $10^{9} / \mathrm{I}$ & $0.02(0.01-0.06)$ & $0.02(0.01-0.03)$ & 0.060 \\
\hline monocyte count, $10^{9} / 1$ & $0.63(0.37-1.12)$ & $0.88(0.57-1.55)^{*}$ & 0.026 \\
\hline Neutrophil percentage, $\%$ & $37.40(26.50-57.30)$ & $49.1(36.6-63.0)^{*}$ & 0.032 \\
\hline Lymphocyte percentage, \% & $53.45(33.35-64.83)$ & $38.5(29.4-54.3)^{*}$ & 0.022 \\
\hline Eosinophil percentage, \% & $1.20(0.60-2.03)$ & $1.1(0.6-1.6)$ & 0.845 \\
\hline Basophil percentage, $\%$ & $0.30(0.10-0.50)$ & $0.2(0.1-0.3)^{*}$ & 0.011 \\
\hline Monocyte percentage, $\%$ & $6.80(4.55-8.63)$ & $8.0(4.9-10.3)^{*}$ & 0.040 \\
\hline Hb level, g/l & $161.00(138.75-179.75)$ & $156(143-167)$ & 0.523 \\
\hline Hematocrit, \% & $50.70(45.40-56.08)$ & $50(45-52)$ & 0.171 \\
\hline$M C V, f l$ & $120.40(113.35-128.70)$ & $120(114-124)$ & 0.549 \\
\hline $\mathrm{MCH}, \mathrm{pg}$ & 38.40 (36.05-39.95) & $38(36-40)$ & 0.582 \\
\hline $\mathrm{MCHC}, \mathrm{g} / \mathrm{l}$ & $315.00(306.75-325.50)$ & $319(307-326)$ & 0.910 \\
\hline RDW, \% & $16.5(15.4-17.8)$ & $15.7(15.3-16.4)$ & 0.079 \\
\hline$M P V, f l$ & $9.4(9.00-9.85)$ & $9.1(8.7-9.4)^{* *}$ & 0.002 \\
\hline PDW, \% & $16.75(16.60-17.10)$ & $16.7(16.4-17.0)$ & 0.273 \\
\hline
\end{tabular}

Data were displayed as median (interquartile range). ${ }^{*} p<0.05$ and ${ }^{* *} p<0.01$ are compared with no BPD group. WBC white blood cell, $R B C$ red blood cell, $H b$ hemoglobin, MCV mean corpuscular volume, MCH mean corpuscular hemoglobin, MCHC mean corpuscular hemoglobin concentration, RDW red cell distribution width, MPV mean platelet volume, $P D W$ platelet distribution width

volume (MPV), basophil percentage and lymphocyte percentage were significantly lower infants with moderate or severe BPD compared with no BPD infants $(9.1$ vs $9.4 \mathrm{fl}$, $p=0.002,0.2 \%$ vs $0.3 \%, p=0.011$ and $38.5 \%$ vs $53.45 \%$, $p=0.022$, respectively).

These potential risk factors were subsequently entered into the multivariable regression model. We found that the risk of moderate-severe BPD was independently associated with intubation at resuscitation (OR 4.020, 95\% CI: 1.124-14.376, $P=0.032$ ), PDA (OR 7.209, 95\% CI: 1.980-26.251, $P=0.003$ ), (suspected) early-onset neonatal sepsis (OR 6.697, 95\% CI: $1.659-27.034, P=0.008$ ) and platelet count (OR 1.011, 95\% CI: $1.002-1.021, P=0.022$, Table 3).

Receiver-operator curve was applied to calculate the cut-off value of the significant continuous variables optimally assessing the risk moderate-severe BPD (Fig. 2). A platelet counts of less than $207 * 10^{9} / 1$ was concluded as the best cut-off value with area under the curve (0.655), sensitivity (0.717), specificity $(0.600)$ and Youden index (0.317). The clinical outcome of this cohort was stratified by the platelet count (Table 4). Besides the effect on the occurrence of moderate and severe BPD, the NICU stay of infants with platelet count $>207 * 10^{9} / 1$ at birth was slightly longer compared with infants with platelet count $\leq 207 * 10^{9} / 1$ at birth (89 (IQR: 62-120) vs 71 (IQR: 50-99), $P=0.048$ ).

\section{Discussion}

The present study systematically analyzed the hematologic parameters at birth in a cohort of extremely premature infants and further evaluated the association between these features and the risk of moderate or severe BPD. We found that the platelet counts at birth were significantly higher in infants developing to moderate-severe BPD in later life. In addition to the well-known risk factors like intubation at resuscitation, PDA and (suspected) early-onset neonatal sepsis, this study showed that platelet count at birth was also an independent risk factor for the occurrence of moderate-severe BPD. Gestational age, may be owing to the population characters, was identified as a non-independent risk factor.

BPD is a severe complication that leads to increased short- and/or long-term morbidity and mortality. Several hematologic parameters during the first days of 
Table 3 Multivariate logistic regression analysis of selected variables associated with BPD

\begin{tabular}{lllll}
\hline Variables & No BPD $(n=55)$ & Moderate or severe BPD $(n=60)$ & $p$ & OR $(95 \% \mathrm{Cl})$ \\
\hline Gestational age, weeks & $27.3(26.1-28.6)$ & $25.8(24.5-26.8)$ & 0.100 & $0.733(0.506,1.062)$ \\
Platelet count, $10^{9} / \mathrm{L}$ & $194.00(131.00-245.00)$ & $228(189-259)$ & 0.022 & $1.011(1.002,1.021)$ \\
(Suspected) Early-onset neonatal sepsis, no & $46(84 \%)$ & $34(57 \%)$ & - & - \\
(Suspected) Early-onset neonatal sepsis, yes & $9(16 \%)$ & $26(43 \%)$ & 0.008 & $6.697(1.659,27.034)$ \\
PDA, no & $45(82 \%)$ & $25(42 \%)$ & - & - \\
PDA, yes & $10(18 \%)$ & $35(58 \%)$ & 0.003 & $7.209(1.980,26.251)$ \\
Intubation at resuscitation, no & $30(55 \%)$ & $7(12 \%)$ & - & - \\
Intubation at resuscitation, yes & $25(45 \%)$ & $53(88 \%)$ & 0.032 & $4.020(1.124,14.376)$ \\
\hline
\end{tabular}

PDA patent ductus arteriosus

life are related to the increased risk of BPD. Palta, M et. al found low neutrophil count $\left(<1^{*} 10^{9} / \mathrm{l}\right)$ predicted the BPD severity level (OR: 1.7, 95\% CI:1.1-2.7) in very low birth weight (VLBW) infants [16], which is opposite to findings in the current study. Noticeably, a neutrophil count of less than $1 * 10^{9} / 1$ was only detected in 5 infants without BPD and 6 infants with moderate-severe BPD. This discrepancy may thus be attributed to the small sample size in current study. Large studies are needed to validate the predictability of neutrophil count at birth for the risk of BPD.
The association of MPV with the risk of BPD was reported in several studies $[9,12]$. Dani et. al found that $\mathrm{MPV}>11 \mathrm{fl}$ at 24-48 $\mathrm{h}$ after birth in infants born earlier than 30 weeks was associated with the occurrence of moderate and severe BPD whereas the MPV and platelet count at birth were comparable in infants with and without moderate-severe BPD [9]. Cekmez et.al also found an increased MPV in the first days of life was associated with the development of BPD group in infants born < 34 weeks or with birth weight $<1500 \mathrm{~g}$ [12]. However, a slightly lower MPV at birth was found in infants

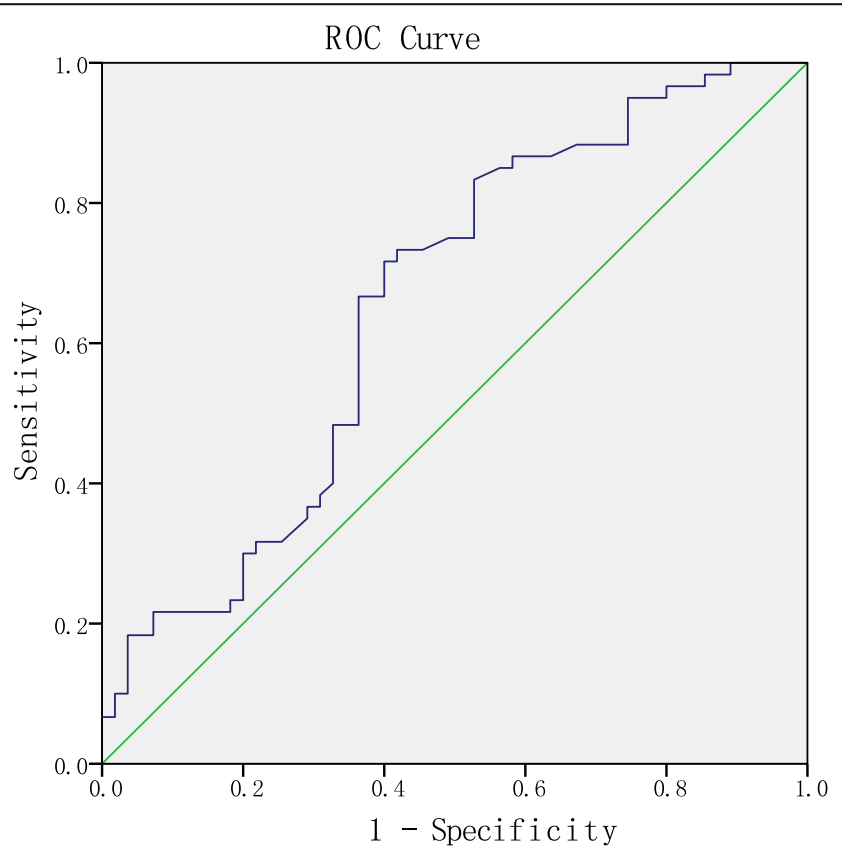

Diagonal segments are produced by ties.

Calculation of cut-off discriminating bronchopulmonary dysplasia status

\begin{tabular}{lccccc}
\hline Variables & AUC & Sensitivity & Specificity & Youden Index & Cut-off value \\
\hline Platelet count, $\mathbf{1 0} / \mathrm{L}$ & 0.655 & 0.717 & 0.600 & 0.317 & 207 \\
\hline
\end{tabular}

Fig. 2 ROC curve of Platelet count with different BPD state and calculation of the cut-off. The cut-off value was calculated to get a maximum Youden's Index (sensitivity+specificity-1) 
Table 4 Stratification of the Clinical outcome of entire cohort by platelet count at birth

\begin{tabular}{llllll}
\hline Variables & Platelet $\leq 207^{*} 10^{9} / I(n=50)$ & Platelet $>207^{*} 10^{9} / I(n=65)$ & Odd Ratio & $95 \% \mathrm{Cl}$ & $\mathrm{P}$ value \\
\hline Moderate or severe BPD & $17(34 \%)$ & $43(50 \%)$ & 3.794 & $(1.742,8.266)$ & 0.001 \\
ROP requiring intervention & $12(24 \%)$ & $19(29 \%)$ & 1.367 & $(0.589,3.177)$ & 0.466 \\
Pulmonary hypertension & $4(8 \%)$ & $7(10.8 \%)$ & 1.270 & $(0.893,1.179)$ & 0.718 \\
IVH grade 3 or 4 & $5(10 \%)$ & $9(13.8 \%)$ & 1.446 & $(0.453,4.621)$ & 0.532 \\
NEC & $1(2 \%)$ & $4(6.2 \%)$ & 3.213 & $(0.348,29.683)$ & 0.386 \\
Hospital Stay & $71(50-99)$ & $89(62-120)$ & - & $(-40.020,10.200)$ & 0.048 \\
\multicolumn{1}{c}{ Death } & $0(0 \%)$ & $1(1.5 \%)$ & - & - & - \\
\hline
\end{tabular}

Data were displayed as median (interquartile range) or number (percentage). $R O P$ retinopathy of prematurity, $I V H$ intraventricular hemorrhage, $N E C$ necrotizing enterocolitis

developing into moderate or severe BPD in current study. These discrepancies may be owing to the different study populations.

It is interesting that the platelet counts at birth was associated with the occurrence of moderate-severe BPD. However, the underlying mechanisms remains to be elucidated. Pulmonary inflammation plays a pivotal role in the arrested lung development following extremely preterm birth $[4,5]$. In a recent study, Sreeramkumar et al. report that activated platelets initiate inflammation through directing of the neutrophil migration [17]. The elimination of platelets in blood remarkably mitigates pulmonary injury in a mice model of acute lung injury [18]. The lung has been recognized as a site of platelet biogenesis [19], leading to the realization that the immature lung may be a fragile organ in case of inflammation. We thus speculate that the inhibition of platelet activation may ameliorate pulmonary inflammation in extremely premature infants.

A newborn's platelet count can be influenced by several factors. Infection and inflammation may increase the platelet shortly and then consume a lot. Antibodies generated by maternal immune system under some pathologic condition may also enter the fetal circulation, attack the platelet and lead to decreased platelet count in newborn [20]. In current study, only 4 infants were born with a platelet count less than $100,000 / \mathrm{uL}$, and none of their mothers had platelet count less than $100,000 / \mathrm{uL}$ on the day of birth. Besides, maternal complications like preeclampsia and intrauterine growth restriction accompanied by chronic hypoxia may stimulate the generation of reticulocytes and reduce the number and total masses of megakaryocyte, as well as blunt the function of platelet [21]. To exclude these confounding factors, we included early onset neonatal sepsis, chorioamnionitis, SGA and gestational hypertension in our analysis.

The main strength of our study is the great applicability in routine practice. BPD remains a major challenge for perinatologists. The accurate and rapid identification of high-risk infants is of paramount importance for the prevention of BPD. However, our data should be interpreted with care. Besides of the retrospective design, an inclusion bias in our study has incurred because we excluded the infants who died before the diagnosis of BPD was made. These infants may be also at increased risk of moderate or severe BPD due to the intubation in most cases prior to death. Moreover, the cut-off value of hematologic parameters at birth was calculated in a relatively small cohort of extremely preterm infants. Large prospective studies are required to confirm the findings in this study. The function of the platelet was not measured in this manuscript. Besides, it would be interesting to have a look at the continuous platelet count in the first week of life and its predictive value for $\mathrm{BPD}$.

\section{Conclusion}

In conclusion, hematologic parameters at birth are different in extremely preterm infants with moderate-severe BPD. A platelet count $>207^{*} 10^{9} / 1$ at birth is an independent predictor for the occurrence of moderate-severe BPD.

\section{Abbreviations}

95\%Cl: 95\% confidence interval; ART: Assisted reproductive technology; BPD: Bronchopulmonary dysplasia; BW: Birth weight; ELBW: Extremely low birth weight; GA: Gestational age; GDM: Gestational diabetes mellitus; $\mathrm{Hb}$ : Hemoglobin; IVH: Intraventricular hemorrhage; MCH: Mean corpuscular Hemoglobin; MCHC: Mean corpuscular hemoglobin concentration; MCV: Mean corpuscular volume; MPV: Mean platelet volume; NEC: Necrotizing enterocolitis; NICU: Neonatal intensive care unit; NRDS: Neonatal respiratory distress syndrome; OR: Odds ratios; PDA: Patent ductus arteriosus; PDW: Platelet distribution width; PPROM: Premature prelabor rupture of membranes; RDW: Red blood cell distribution width; ROC: Receiver-operator curve; ROP: Retinopathy of prematurity

\section{Acknowledgements}

We kindly acknowledged Panpan Sun for the advice on statistics used in the study.

\section{Funding}

This study is supported by the Shenzhen Health and Family Planning Commission (SZBC2018011), Shenzhen Science and Technology Innovation Committee (JCYJ20160429102107498) and Shenzhen Medical Sanming Project (SZSM201612045). The funders were not involved in the study design, data collection, analysis, interpretation, or manuscript preparation. 


\section{Availability of data and materials}

The raw dataset analyzed in the current study are available from the corresponding author on reasonable request.

\section{Authors' contributions}

FW, CY, and XC conceptualized and designed the study, and wrote the first draft of the manuscripts. XC, HL and XQ carried out the clinical data collection and data analysis. FW and CY reviewed and revised the manuscripts. All authors read and approved the final manuscript.

\section{Ethics approval and consent to participate}

The Shenzhen Maternity and Child Health Care Hospital Institutional Ethical Committee approved the collection and usage of the clinical information for research purposes before the investigation was initiated and waived the requirement for informed consent (IEC No. [2018]-082).

\section{Consent for publication}

Not applicable.

\section{Competing interests}

The authors declare that they have no competing interests.

\section{Publisher's Note}

Springer Nature remains neutral with regard to jurisdictional claims in published maps and institutional affiliations.

\section{Author details}

'Department of Neonatology, Affiliated Shenzhen Maternity \& Child Healthcare Hospital, Southern Medical University, Shenzhen, China. ${ }^{2}$ Department of Pediatrics, David Geffen School of Medicine, University of California Los Angeles, Los Angeles, CA, USA. ${ }^{3}$ Los Angeles Biomedical Research Institute at Harbor-UCLA Medical Center, Torrance, CA, USA.

Received: 25 November 2018 Accepted: 18 April 2019

Published online: 30 April 2019

\section{References}

1. Lapcharoensap W, Gage SC, Kan P, Profit J, Shaw GM, Gould JB, Stevenson DK, O'Brodovich H, Lee HC. Hospital variation and risk factors for bronchopulmonary dysplasia in a population-based cohort. JAMA Pediatr. 2015;169(2):e143676.

2. Kobaly K, Schluchter M, Minich N, Friedman H, Taylor HG, Wilson-Costello D, Hack M. Outcomes of extremely low birth weight $(<1 \mathrm{~kg})$ and extremely low gestational age ( $<28$ weeks) infants with bronchopulmonary dysplasia: effects of practice changes in 2000 to 2003. Pediatrics. 2008;121(1):73-81.

3. Voynow JA. "new" bronchopulmonary dysplasia and chronic lung disease. Paediatr Respir Rev. 2017;24:17-8.

4. Bui CB, Pang MA, Sehgal A, Theda C, Lao JC, Berger PJ, Nold MF, Nold-Petry CA. Pulmonary hypertension associated with bronchopulmonary dysplasia in preterm infants. J Reprod Immunol. 2017;124:21-9.

5. Kinsella JP, Greenough A, Abman SH. Bronchopulmonary dysplasia. Lancet (London, England). 2006;367(9520):1421-31.

6. Laughon MM, Langer JC, Bose CL, Smith PB, Ambalavanan N, Kennedy KA, Stoll BJ, Buchter S, Laptook AR, Ehrenkranz RA, et al. Prediction of bronchopulmonary dysplasia by postnatal age in extremely premature infants. Am J Respir Crit Care Med. 2011;183(12):1715-22.

7. Joshi S, Kotecha S. Lung growth and development. Early Hum Dev. 2007; 83(12):789-94.

8. Davidson LM, Berkelhamer SK. Bronchopulmonary Dysplasia: Chronic lung disease of infancy and long-term pulmonary outcomes. J Clin Med. 2017; 6(1):4.

9. Dani C, Poggi C, Barp J, Berti E, Fontanelli G. Mean platelet volume and risk of bronchopulmonary dysplasia and intraventricular hemorrhage in extremely preterm infants. Am J Perinatol. 2011;28(7):551-6.

10. Steinhorn R. When does BPD begin? J Pediatr. 2017;187:3.

11. Balany J, Bhandari V. Understanding the impact of infection, inflammation, and their persistence in the pathogenesis of bronchopulmonary dysplasia. Front Med. 2015;2:90.

12. Cekmez F, Tanju IA, Canpolat FE, Aydinoz S, Aydemir G, Karademir F, Sarici SU. Mean platelet volume in very preterm infants: a predictor of morbidities? Eur Rev Med Pharmacol Sci. 2013;17(1):134-7.
13. Ehrenkranz RA, Walsh MC, Vohr BR, Jobe AH, Wright LL, Fanaroff AA, Wrage $L A$, Poole K. Validation of the National Institutes of Health consensus definition of bronchopulmonary dysplasia. Pediatrics. 2005;116(6):1353-60.

14. Walsh MC, Wilson-Costello D, Zadell A, Newman N, Fanaroff A. Safety, reliability, and validity of a physiologic definition of bronchopulmonary dysplasia. J Perinatol: official journal of the California Perinatal Association. 2003;23(6):451-6.

15. Gad Gl, Abushady NM, Fathi MS, Elsaadany W. Diagnostic value of antimicrobial peptide, cathelicidin in congenital pneumonia. J Matern Fetal Neonatal Med. 2015;28(18):2197-200.

16. Palta M, Sadek-Badawi M, Carlton DP. Association of BPD and IVH with early neutrophil and white counts in VLBW neonates with gestational age $<32$ weeks. J Perinatol: official journal of the California Perinatal Association. 2008;28(9):604-10

17. Sreeramkumar V, Adrover JM, Ballesteros I, Cuartero MI, Rossaint J, Bilbao I, Nacher M, Pitaval C, Radovanovic I, Fukui Y, et al. Neutrophils scan for activated platelets to initiate inflammation. Science (New York, NY). 2014; 346(6214):1234-8.

18. Looney MR, Gilliss BM, Matthay MA. Pathophysiology of transfusion-related acute lung injury. Curr Opin Hematol. 2010;17(5):418-23.

19. Lefrancais E, Ortiz-Munoz G, Caudrillier A, Mallavia B, Liu F, Sayah DM, Thornton EE, Headley MB, David T, Coughlin SR, et al. The lung is a site of platelet biogenesis and a reservoir for haematopoietic progenitors. Nature. 2017;544(7648):105-9.

20. Bonstein L, Haddad N. Taking a wider view on fetal/neonatal alloimmune thrombocytopenia. Thromb Res. 2017;151(Suppl 1):S100-s102.

21. Tyagi T, Ahmad S, Gupta N, Sahu A, Ahmad Y, Nair V, Chatterjee T, Bajaj N, Sengupta S, Ganju L, et al. Altered expression of platelet proteins and calpain activity mediate hypoxia-induced prothrombotic phenotype. Blood. 2014;123(8):1250-60

Ready to submit your research? Choose BMC and benefit from:

- fast, convenient online submission

- thorough peer review by experienced researchers in your field

- rapid publication on acceptance

- support for research data, including large and complex data types

- gold Open Access which fosters wider collaboration and increased citations

- maximum visibility for your research: over $100 \mathrm{M}$ website views per year

At BMC, research is always in progress.

Learn more biomedcentral.com/submissions 